\title{
Enhanced oral bioavailability of a sterol-loaded microemulsion formulation of Flammulina velutipes, a potential antitumor drug
}

This article was published in the following Dove Press journal:

International Journal of Nanomedicine

17 September 2012

Number of times this article has been viewed

\section{Chengxue Yi* \\ Hui Zhong* \\ Shanshan Tong* \\ Xia Cao* \\ Caleb K Firempong \\ Hongfei Liu \\ Min Fu \\ Yan Yang \\ Yingshu Feng \\ Huiyun Zhang \\ Ximing Xu \\ Jiangnan Yu}

Department of Pharmaceutics, School of Pharmacy, Center for Nano Drug/

Gene Delivery and Tissue Engineering, jiangsu University, Zhenjiang,

People's Republic of China

*These authors contributed equally to this work
Correspondence: Ximing Xu; jiangnan Yu Department of Pharmaceutics, School of Pharmacy, Center for Nano Drug/Gene Delivery and Tissue Engineering, Jiangsu University, Zhenjiang 21200I,

People's Republic of China

Tel +865II 8503845 I

$\mathrm{Fax}+8651 \mid 8503845$ I

Email xmxu@ujs.edu.cn; yjn@ujs.edu.cn
Purpose: To investigate the growth inhibition activity of Flammulina velutipes sterol (FVS) against certain human cancer cell lines (gastric SGC and colon LoVo) and to evaluate the optimum microemulsion prescription, as well as the pharmacokinetics of encapsulated FVS.

Methods: Molecules present in the FVS isolate were identified by gas chromatography/mass spectrometry analysis. The cell viability of FVS was assessed with methyl thiazolyl tetrazolium (MTT) bioassay. Based on the solubility study, phase diagram and stability tests, the optimum prescription of F. velutipes sterol microemulsions (FVSMs) were determined, followed by FVSMs characterization, and its in vivo pharmacokinetic study in rats.

Results: The chemical composition of FVS was mainly ergosterol (54.8\%) and 22,23-dihydroergosterol (27.9\%). After 72 hours of treatment, both the FVS (half-maximal inhibitory concentration $\left[\mathrm{IC}_{50}\right]=11.99 \mu \mathrm{g} \cdot \mathrm{mL}^{-1}$ ) and the standard anticancer drug, 5-fluorouracil $\left(\mathrm{IC}_{50}=0.88 \mu \mathrm{g} \cdot \mathrm{mL}^{-1}\right)$ exhibited strong in vitro antiproliferative activity against SGC cells, with $\mathrm{IC}_{50}>30.0 \mu \mathrm{g} \cdot \mathrm{mL}^{-1}$; but the FVS performed poorly against LoVo cells $\left(\mathrm{IC}_{50}>40.0 \mu \mathrm{g} \cdot \mathrm{mL}^{-1}\right)$. The optimal FVSMs prescription consisted of 3.0\% medium chain triglycerides, $5.0 \%$ ethanol, $21.0 \%$ Cremophor EL and $71.0 \%$ water $(\mathrm{w} / \mathrm{w})$ with associated solubility of FVS being $0.680 \mathrm{mg} \cdot \mathrm{mL}^{-1}$ as compared to free FVS $\left(0.67 \mu \mathrm{g} \cdot \mathrm{mL}^{-1}\right)$. The relative oral bioavailability (area-under-the-curve values of ergosterol and 22,23-dihydroergosterol showed a 2.56-fold and 4.50-fold increase, respectively) of FVSMs (mean diameter $\sim 22.9 \mathrm{~nm}$ ) as against free FVS were greatly enhanced.

Conclusion: These results indicate that the FVS could be a potential candidate for the development of an anticancer drug and it is readily bioavailable via microemulsion formulations.

Keywords: Flammulina velutipes sterol, microemulsions, pharmacokinetics, bioavailability

\section{Introduction}

Flammulina velutipes (Curt. ex Fr.) Sing belongs to the genus Flammulina (or Collybia) of Tricholomataceae of Agaricales of Hymenomycetes of Basidiomycotina of Eumycota. The mycelia or fruiting body of $F$. velutipes can be used as food or drugs for mankind. Many studies have long reported the characteristics, nutritional components and biological activities of $F$. velutipes. ${ }^{1-9} F$. velutipes is rich in macromolecules such as proteins, polysaccharides, and glycoproteins with its associated medicinal qualities such as its antivirus, antitumor, and immunomodulatory activity. ${ }^{4,10}$ In recent times even though some simple biological molecules including sterols, fatty acids, flavonoids, nucleosides, and polyol have been found in F. velutipes, ${ }^{11}$ the antitumor activities of these substances have been scarcely reported. 
Our laboratory has been able to screen out lipid soluble sterols with an antitumor effect from $F$. velutipes by lipidraft chromatography, which was found to be linked to the tyrosine kinase receptor (data not published). In this study, our laboratory was interested in performing a preliminary investigation of the anticancer potential and bioavailability of $F$. velutipes sterol (FVS) as an in-depth contribution to the research of $F$. velutipes. FVS is a white powder, which can easily dissolve in ether, chloroform, hot ethanol, and other organic solvents, but barely dissolves in water. As a result, it is necessary to find a method to improve the solubility and oral bioavailability of this sterol.

Microemulsions are thermodynamically stable nanometer systems with characteristics of easy preparation, small droplet size, low viscosity, and strong solubilization effect. ${ }^{12}$ It is formed spontaneously by water, oil, surfactant and cosurfactant. ${ }^{13,14}$ According to the structure of a microemulsion, it can be divided into water-in-oil (w/o), oil-in-water (o/w) and bicontinuous microemulsion. ${ }^{15}$ As a drug carrier, a microemulsion can increase the solubility and oral bioavailability of poorly soluble drugs, ameliorate the localization, improve systemic delivery of the drug, and possess the ability of targeting drug release. ${ }^{16-18}$ The absolute bioavailability of a poorly soluble drug cyclosporin A which was loaded into a microemulsion system was increased to about 3.3- and 1.25fold compared with free Sandimmun and Sandimmun Neoral (Novartis, Basel, Switzerland), which were used as commercial cyclosporin A. ${ }^{19}$ In addition, it has been confirmed that the microemulsion system containing the poorly soluble drug docetaxel could improve the solubilization property and oral bioavailability of the drug. ${ }^{20}$

Presently, there are very few in vivo studies on FVS due to some major difficulties of the material such as its solubility, bioavailability, and interferences from other endogenous substances. Nevertheless, for the first time, this study has been able to overcome these obstacles and to successfully establish a prescription method for the formulation of F. velutipes sterol microemulsions (FVSMs). Furthermore, the pharmacokinetic study on the FVSMs in rats also showed an enhanced bioavailability of the sterol.

\section{Materials and methods Biological materials, cancer cell lines, and chemicals}

F. velutipes was kindly supplied by Zhengdong Ecological Agriculture Development Center (Jiangsu, China) and airdried at $55^{\circ} \mathrm{C}$ before use. Human gastric cancer cell SGC and colon carcinoma cell LoVo were obtained from Cell Bank of
Academy of Science (Shanghai, China). MTT and trypsin were purchased from Beyotime Institute of Biotechnology (Jiangsu, China). Fetal bovine serum and Dulbecco's modified Eagle's medium (DMEM) were purchased from Gibco (Grand Island, NY). 5-fluorouracil was supplied by Jin Yao Amino Acid Co, Ltd (Tianjin, China). Ergosterol of 98\% purity was bought from Acros Organics (Geel, Belgium). Ergine of 98\% purity was purchased from Xili Biotechnology Co, Ltd (Yunnan, China). 22,23-dihydroergosterol was prepared in our laboratory. Since 22,23-dihydroergosterol was not available in the market, it was prepared by our laboratory from $F$. velutipes. Briefly, the FVS extract was prepared as described in the following "Extraction of FVS" section. Then 22,23-dihydroergosterol was isolated using preparative reversed phase high-pressure liquid chromatography (HPLC) from the FVS extract. The 22.23-dihydroergosterol we was evaluated with IR, ${ }^{1} \mathrm{H}-\mathrm{NMR}$ and ${ }^{13} \mathrm{C}$-NMR to confirm its structure and suitability for serving as a reference sterol. Tween 80, PEG400, ethanol, and isopropyl myristate (IPM) were purchased from Sinopharm Chemical Reagent Co, Ltd (Shanghai, China). Cremophor RH40 and Cremophor EL were bought from BASF (Ludwigshafen, Germany). Medium chain triglycerides (MCT) and soybean oil were purchased from Tieling Beiya Medicinal Oil Co, Ltd (Tieling, China). Pure chromatographic methanol was obtained from Hanbon Science and Technology (Jiangsu, China). Analytical grade ether was purchased from Kelong Chemical Reagent Factory (Chengdu, China). All the other chemicals and reagents used in this study were of analytical grade and obtained commercially.

\section{Extraction of FVS}

Dried $F$. velutipes powder $(0.7 \mathrm{~kg})$ was extracted two times with $1 \mathrm{~L}$ of $95 \%$ ethanol at $85^{\circ} \mathrm{C}$ for 2 hours. The extract was concentrated under pressure using a rotary vacuum evaporator to obtain the residue. Water was added to the residue and stirred thoroughly to form a uniform mixture. The mixture was then taken through ethyl ether extraction and finally concentrated to give a residual mass of $10 \mathrm{~g}$. After that, the resulting product was refluxed with $1 \mathrm{~mol} \cdot \mathrm{L}^{-1} \mathrm{KOH}$ and $95 \%$ ethanol under the following conditions which included heating at $80^{\circ} \mathrm{C}$ and simultaneous stirring for 3 hours. This was followed by decompression drying and the dissolution of the product in water. The ethyl ether extraction procedure was repeated five times. The mixture obtained was washed with double distilled water until the $\mathrm{pH}$ was 7.0, and further rewashed with full oscillation using $\mathrm{KOH}\left(0.5 \mathrm{~mol} \cdot \mathrm{L}^{-1}\right)$ three times. The resulting mixture was once again washed with double distilled water until the $\mathrm{pH}$ was 7.0. The neutral 
solution was dehydrated with anhydrous sodium sulfate and then filtered through $0.22 \mu \mathrm{m}$ membrane. After the evaporation of ethyl ether, the crude FVS extract was obtained, and subsequently refined by dissolving it in hot ethanol. This was then followed by crystallization at $4^{\circ} \mathrm{C}$ and filtration to obtain refined FVS.

\section{Chemical composition analysis of FVS}

The refined FVS extract was chemically analyzed with gas chromatography/mass spectrometry (GC-MS; Varian, Walnut Creek, CA). The gas chromatographic condition was as follows: DB-5 ms $(30.0 \mathrm{~m} \times 250 \mu \mathrm{m} \times 0.25 \mu \mathrm{m})$, carrier gas was a high purity helium; flow rate was $1.0 \mathrm{~mL} \cdot \mathrm{min}^{-1}$; the injection port temperature was $300^{\circ} \mathrm{C}$; the initial column temperature was $240^{\circ} \mathrm{C}$ and then the column temperature was set to $285^{\circ} \mathrm{C}$ (kept for $30 \mathrm{~min}$ ) at the rate of $15^{\circ} \mathrm{C} \cdot \mathrm{min}^{-1}$; the injection volume was $10 \mu \mathrm{L}$. In addition, the mass spectrometer condition was as stated: ionization source was $\mathrm{EI}+$; ionization energy was $70 \mathrm{eV}$; temperature of ionization source was $200^{\circ} \mathrm{C}$; transfer line temperature was $290^{\circ} \mathrm{C}$; quality scan range was 40-660 amu.

\section{In vitro cell viability assay}

All the human cancer cell lines (SGC and LoVo) were cultured in DMEM medium, supplemented with $10 \%$ fetal calf serum in culture flasks at $37^{\circ} \mathrm{C}$ and in a $5 \%$ humidified $\mathrm{CO}_{2}$ incubator. The cells at exponential growth phase were then digested with trypsin which was followed by centrifugation at $1500 \mathrm{rpm}$ for 5 minutes. The cells were further subcultured in another medium and its concentration adjusted to $2 \times 10^{4} \mathrm{~mL}^{-1}$. After that $100 \mu \mathrm{L}$ of the cells were seeded into each well of a $96-$ well plate and incubated for 24 hours. The cells were divided into four groups: the untreated, vehicle, treated, and positive control groups. An aliquot $(20 \mu \mathrm{L})$ each of $0.5 \%$ DMSO, FVS $\left(1.0,3.0,5.0,10.0,15.0,20.0 \mu \mathrm{g} \cdot \mathrm{mL}^{-1}\right)$, and 5-fluorouracil $\left(1.0,3.0,5.0,10.0,15.0,20.0 \mu \mathrm{g} \cdot \mathrm{mL}^{-1}\right)$ were added to the vehicle, treated, and positive control groups, respectively. The FVS was dissolved in DMSO, and the final concentration of the DMSO was kept below $0.1 \%(\mathrm{v} / \mathrm{v})$ of the culture medium. However, the 5-fluorouracil was dissolved in the DMEM. The cells in each group were further divided into three subgroups (A, B, and C). MTT $\left(20 \mu \mathrm{L}, 5 \mathrm{mg} \cdot \mathrm{mL}^{-1}\right)$ was added to A, B, and $\mathrm{C}$ at various time points $(24,48$, and 72 hours, respectively) and the cells incubated for a further 4 hours. DMSO $(100 \mu \mathrm{L})$ was later added into each well to solubilize the formazan crystals. The absorbances were read at $570 \mathrm{~nm}$ using a microplate reader (Spectra III, SLT Instruments, Kernenmunster, Austria). All determinations were carried out in triplicate. The inhibitory rate $(I R)$ of the cell proliferation was calculated according to the following equation:

$$
I R(\%)=\left(1-\frac{A}{A^{\prime}}\right) \times 100 \%
$$

where $A$ refers to the absorbance of treated group and $A^{\prime}$ refers to the absorbance of untreated group. The concentration of the samples that killed $50 \%$ of the cells $\left(\mathrm{IC}_{50}\right)$ was calculated by Curve-Expert 1.3 (Daniel G Hyams, Hixson, TN).

\section{Optimized preparation of FVSMs}

\section{Phase diagram preparation}

The investigation of the ternary phase diagrams was as described by other previous studies with some slight modification. ${ }^{21,22}$ The phase diagram was used to assess the influence of different factors on the formation of the microemulsion and to determine the predominant microemulsion domains. Software Origin 7.0 (OriginLab Corp, Northampton, MA) was used to draw the ternary phase diagrams. The surfactants (ie, Tween 80, Cremophor EL, and Cremophor RH40) and cosurfactants (ie, PEG400 and ethanol) were weighed at different ratios, mixed thoroughly and then stirred to make the surfactant-cosurfactant mixture $\left(S_{\text {mix }}\right)$. After that, the oil phase and $S_{\text {mix }}$ were mixed together, where the fraction of oil was fixed at $10 \%(\mathrm{w} / \mathrm{w})$. Double distilled water was added dropwise into every kind of clear oil and $S_{\text {mix }}$ mixture with gentle stirring to allow equilibration. The different times taken for the various solutions to change from clear to turbid appearance were noted as the critical points. The respective mass fraction of surfactant, cosurfactant, and double distilled water at these critical points were then used to construct the phase diagrams for the determination of microemulsion domain.

\section{Optimization of blank microemulsion prescription}

The method employed for the optimization of blank microemulsion prescription was as described in other studies. $^{23-25}$

\section{Solubility study}

The solubility of FVS in different vehicles was determined by adding $40 \mathrm{mg}$ of FVS into $1 \mathrm{~mL}$ of each vehicle in the centrifugal tube, followed by mixing in a shaker incubator at $37^{\circ} \mathrm{C}$ for 72 hours. The mixture was then centrifuged at $10,000 \mathrm{rpm}$ for 10 minutes to remove the excess FVS. After that, the concentration of FVS in the solubilized system was measured by HPLC. 


\section{Screening of cosurfactant}

The effects of PEG400 and ethanol as cosurfactants on the formation of the microemulsion domain were investigated with the aid of the ternary phase diagram. The ratios of the surfactant and cosurfactant were varied from 9:1 to 1:9 with the fraction of oil being fixed at $10 \%(\mathrm{w} / \mathrm{w})$ of the $S_{\text {mix }}$. Thus the different ratios of $S_{\text {mix }}(1 \mathrm{~g})$ and oil $(0.1 \mathrm{~g})$ were put together for this study. Under stirring at $37^{\circ} \mathrm{C}$, double distilled water was added dropwise into the oil and $S_{\text {mix }}$ mixture until a critical point was reached. The outcome was then used to construct the ternary phase diagram as described in the "phase diagram preparation" section and analyzed appropriately to select a suitable cosurfactant.

Determination of the best ratios of oil to $S_{\text {mix }}$ and surfactant to cosurfactant

The effect of $K$ (the mass ratio of oil to $S_{\text {mix }}$ ) and $K_{\mathrm{m}}$ (the mass ratio of surfactant to cosurfactant) were investigated. The ratio of surfactant to cosurfactant was fixed at 9:1 and that of oil to $S_{\text {mix }}$ varied from 9:1 to 1:9 in order to choose the best ratio of $K$. Nine blank microemulsions were also prepared with the best $K$ ratio to determine the best ratio of $K_{\mathrm{m}}$ in different surfactant groups $\left(K_{\mathrm{m}}=5: 5,7: 3,9: 1\right.$ in the Cremophor EL group, $K_{\mathrm{m}}=6: 4,8: 2,9: 1$ in the Cremophor RH40 group, and $K_{\mathrm{m}}=7: 3,8: 2,9: 1$ in the Tween 80 group). The droplet sizes of the nine blank microemulsions were measured and taken through accelerated high temperatures at $40^{\circ} \mathrm{C}$ and $60^{\circ} \mathrm{C}$ for 10 days to observe the stability of the microemulsions. The best ratios of $K$ and $K_{\mathrm{m}}$ were then selected for further studies.

\section{Preliminary screening of surfactants}

Based on the best ratios of $K$ and $K_{\mathrm{m}}$ with the respective surfactant, the blank microemulsions with acceptable droplet sizes were chosen for further studies.

\section{Selection of optimum FVSMs prescription}

Based on the results of the optimized blank microemulsions with the aid of the ternary phase diagrams, the two prescriptions (A and B) of FVSMs were established. FVSMs were prepared according to the methods described by other studies with some slight modification. ${ }^{26}$ Briefly, the surfactant was mixed with oil according to the different prescriptions established. This was followed by the addition of the cosurfactant and FVS to the mixture to obtain a clear solution. The double distilled water was then added dropwise into the resulting mixture and stirred vigorously using a magnetic stirrer until the system was clear and transparent. The resulting FVSMs were tightly sealed and stored at ambient temperature. The stability of the microemulsion formulations was then determined by observing periodically the occurrence of phase separation. The optimum prescription was selected from prescriptions A and B based on the stability assay of accelerated high temperature and long-term studies.

\section{Accelerated high temperature experiment}

The prepared FVSMs prescription A and B were sealed in centrifuge tubes at $25^{\circ} \mathrm{C}, 40^{\circ} \mathrm{C}$, and $60^{\circ} \mathrm{C}$. The stability of the sterol-loaded microemulsion was analyzed by determining the content of ergosterol and 22,23-dihydroergosterol using HPLC after 6 and 12 days. Briefly, the supernatant $(0.5 \mathrm{~g})$ of FVSMs ( $5 \mathrm{~mL}, 0.58 \mathrm{mg} \cdot \mathrm{mL}^{-1}$ ) which was obtained from high-speed centrifugation at $10,000 \mathrm{rpm}$ for 10 minutes was put into a $10 \mathrm{~mL}$ volumetric flask and topped up with methanol to the maximum mark. The resulting mixture was filtered and the filtrate used as samples. Ergosterol and 22,23-dihydroergosterol were used as reference sterols. The chromatographic condition was as follows: the column was Inertsil ODS-SP (250 mm $\times 4.6 \mathrm{~mm}, 5 \mu \mathrm{m})$; mobile phase was 98\% methanol; the flow rate was $1.0 \mathrm{~mL} \cdot \mathrm{min}^{-1}$; the detection wavelength was $282 \mathrm{~nm}$ and the column temperature was $25^{\circ} \mathrm{C}$.

\section{Long-term experiment}

An aliquot of $0.58 \mathrm{mg} \cdot \mathrm{mL}^{-1} \mathrm{FVSMs}$ (each of prescriptions $\mathrm{A}$ and B) was sealed in centrifuge tubes at $25^{\circ} \mathrm{C}$ for 30 days and the stability of FVSMs was evaluated by observing the occurrence of phase separation.

\section{Characterization of FVSMs Type of microemulsion}

The type of microemulsion was identified by the staining method. The water-soluble dye methylene blue and the oilsoluble dye Sudan red were equally added onto the blank microemulsion and FVSMs to evaluate the diffusion speed of the two dyes. If the blue dye diffuses faster than the red dye, then the type of microemulsion is $\mathrm{o} / \mathrm{w}$, and vice versa for the w/o.

\section{Droplet size distribution and zeta potential}

Three milliliters of $0.68 \mathrm{mg} \cdot \mathrm{mL}^{-1}$ optimized FVSM prescription was used for the measurement of the mean droplet size and the distribution using the high concentration mode of laser particle size analyzer (BI-9000, Brookhaven, Upton, NY). Furthermore, the zeta potential of the microemulsion was determined using a ZetaPlus Zeta Potential Analyzer (Brookhaven).

\section{Morphological observation}

The morphology of the microemulsion was examined by transmission electron microscopy (TEM; JEM-2100; JEOL, 
Tokyo, Japan). The copper mesh (400) containing the drops of diluted FVSMs solution was stained with $2 \%$ phosphotungstic acid (PTA) and dried at room temperature to form a thin film for assessment.

\section{Rheological study}

The rheological property of FVSMs $\left(0.68 \mathrm{mg} \cdot \mathrm{mL}^{-1}\right)$ was studied with the aid of a Brookfield LV viscometer, equipped with spindle SC4-18 (Brookfield Engineering Laboratories, Sloughton, MA). By using the viscometer, the viscosity, spindle speed, shear stress, shear rate, and temperature were recorded. The measurements were repeated nine times and the average of the respective values used in calculating the apparent viscosity.

\section{Content determination}

FVSMs $\left(2 \mathrm{~mL}, 0.68 \mathrm{mg} \cdot \mathrm{mL}^{-1}\right)$ were diluted by double distilled water $(4 \mathrm{~mL})$ and filtered through a $0.22 \mu \mathrm{m}$ membrane. The filtrate was put into a $10 \mathrm{~mL}$ volumetric flask and topped up with an additionally pure chromatographic methanol to the maximum volume. The content of ergosterol and 22,23-dihydroergosterol was detected by HPLC. The chromatographic condition was as described in the "Selection of optimum FVSMs prescription" section.

\section{Encapsulation efficiency of FVS-loaded microemulsion}

The content of FVS encapsulated within the microemulsion was measured according to a slight modification of the method described previously. ${ }^{27,28}$ The microemulsion preparation $\left(0.11 \mathrm{mg} \cdot \mathrm{mL}^{-1}\right)$ was poured onto a $0.22 \mu \mathrm{m}$ cellulose nitrate membrane to remove the nonencapsulated FVS. The free FVS was retained in the membrane while the filtrate containing the homogeneous suspension of FVSMs was collected. The concentrations of free FVS, FVS-loaded microemulsion, and external standards were diluted with 98\% methanol mobile phase and mixed thoroughly for HPLC injection. The HPLC was then used to measure the total content of ergosterol in the different samples and based on that measurement, the encapsulation efficiency $(E E \%)$ was calculated as follows: $E E \%=C_{1} / C_{2} \cdot 100 \%$, where $C_{1}$ is the mass of ergosterol in FVSMs after filtration, and $C_{2}$ is the total mass of ergosterol in FVS.

\section{Stability of FVSMs}

Accelerated centrifugal test

The phase dispersion of FVSMs $\left(0.68 \mathrm{mg} \cdot \mathrm{mL}^{-1}\right)$ was observed at an accelerated centrifugation of 10,000 rpm for 10 minutes at $4^{\circ} \mathrm{C}$.

\section{Dilution test}

The FVSMs $\left(0.68 \mathrm{mg} \cdot \mathrm{mL}^{-1}\right)$ was diluted 100 times with double distilled water at $25^{\circ} \mathrm{C}$ for 24 hours. The solution was centrifuged at $10,000 \mathrm{rpm}$ for 10 minutes to remove the precipitated FVS, if any. The FVSMs were then observed for their clear, transparent, and nonprecipitated characteristics.

\section{Low temperature test}

The FVSMs $\left(0.68 \mathrm{mg} \cdot \mathrm{mL}^{-1}\right)$ were stored at $4^{\circ} \mathrm{C}$ for 21 days. The stability was investigated by observing the occurrence of the dispersed phase or crystals after centrifugation. This was followed by the determination of the FVS content of the formulated microemulsions using HPLC.

\section{In vivo studies}

\section{Animals}

Male Sprague-Dawley rats (220 250 g) were provided by the Laboratory Animal Centre of Jiangsu University (Zhenjiang, China). All the animals were fasted for 12 hours before used for the studies, but allowed free access to water. At room temperature $\left(22^{\circ} \mathrm{C} \pm 2{ }^{\circ} \mathrm{C}\right)$, the rats were also exposed daily to light at predetermined time intervals for 12 hours. The animal study procedures were approved by the Jiangsu University Animal Ethics and Experimentation Committee according to the requirements of the Prevention of Cruelty to Animals Act 1986, under the guidelines of the National Health and Medical Research Council for the Care and Use of Animals for Experimental Purposes in China.

\section{Pharmacokinetic studies of FVSMs in rats}

Ten rats were divided equally into two groups for the oral pharmacokinetic studies of FVSMs. A dose of $100 \mathrm{mg} \cdot \mathrm{kg}^{-1}$ each of FVSMs $\left(5 \mathrm{mg} \cdot \mathrm{mL}^{-1}\right)$ and free FVS $\left(5 \mathrm{mg} \cdot \mathrm{mL}^{-1}\right)$ were administered orally. The free FVS was suspended in $0.5 \%$ (w/v) CMC-Na solution. The blood samples $(0.5 \mathrm{~mL}$ each) were taken from the eye orbit veins after the oral administration at different times $(1,2,3,4,5,6,8,10,12$, 14,16 , and 24 hours) and then put into heparinized tubes. Throughout the study, the blood samples were expertly taken from the same rats without being sacrificed until the 24th hour. For the first six time points, the animals were anesthetized in ether gas before their blood samples were taken for the studies. The plasma samples were obtained by centrifugation of the whole blood at $4000 \mathrm{rpm}$ for 10 minutes. Samples were then treated and the sterol content determined by HPLC. 


\section{Treatment of plasma sample}

The plasma sample $(0.2 \mathrm{~mL})$ and the internal standard $(0.1 \mathrm{~mL})$ were mixed together thoroughly into a $10 \mathrm{~mL}$ centrifuge tube. Pure methanol $(1 \mathrm{~mL})$ was immediately added to the mixture to precipitate the proteins. This was followed by vigorous vortexing with tight plug for 5 minutes. The mixture was centrifuged at $3000 \mathrm{rpm}$ for 10 minutes, after which the supernatant was withdrawn and dried by nitrogen at $40^{\circ} \mathrm{C}$ on a water bath. The residue was dissolved in mobile phase $(0.2 \mathrm{~mL})$ and centrifuged at $10,000 \mathrm{rpm}$ for another 10 minutes. The supernatant was again taken and used for the FVS content determination by HPLC.

\section{In vivo chromatographic conditions}

An Inertsil ODS-SP $(250 \mathrm{~mm} \times 4.6 \mathrm{~mm}, 5 \mu \mathrm{m})$ column was used. The mobile phase for the blood samples was $96 \%$ methanol solution. The flow rate was $1.0 \mathrm{~mL} \cdot \mathrm{min}^{-1}$ and the detection wavelength was $282 \mathrm{~nm}$. Other conditions include injection volume $(20 \mu \mathrm{L})$, internal standard (ergine, Figure 1C), and detection sensitivity (0.02 AUFS).

The plasma concentrations at different time points were calculated using the standard curve and consequently, the various pharmacokinetic parameters were obtained.

\section{Results and discussion}

\section{Chemical composition and in vitro anticancer activity}

The antitumor effect of FVS was preliminarily found with lipid-raft chromatography (data not published). The FVS extract consisted of mainly ergosterol (54.78\%, Figure 1A), 22,23dihydroergosterol (27.94\%, Figure 1B), ergosta-5,8,22-triene3 -ol (11.27\%) and ergost-8(14)-ene-3 $\beta$-ol (5.24\%) according to the GC-MS results. This outcome was generally consistent

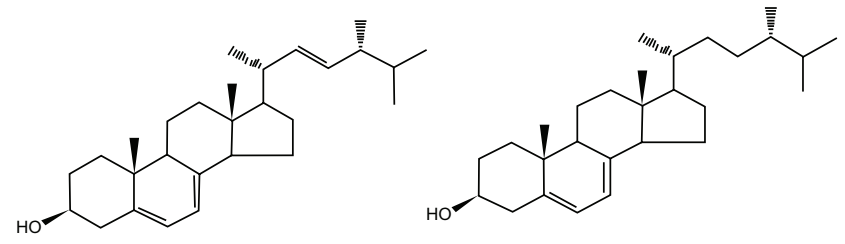

A

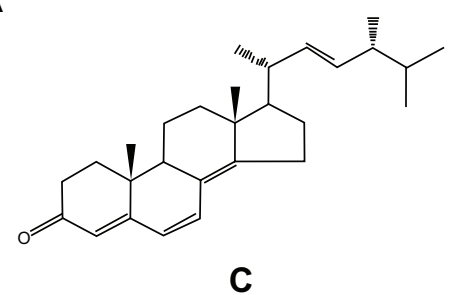

B

Figure I Chemical structures of ergosterol (A), 22,23-dihydroergosterol (B), and ergine (C). with previous studies. ${ }^{3,29}$ The MTT bioassay showed that FVS strongly inhibited the growth of human tumor cells SGC (Figure 2). The increasing time-dependent inhibition rate of SGC was $30.45 \%, 39.91 \%$ and $68.15 \%$ at 24,48 , and 72 hours, respectively, which also followed the same trend as the standard 5-fluorouracil (47.88\%, 56.21\%, and 64.87\%, respectively). This result confirms the desirable antitumor activity of FVS. Similarly, the $\mathrm{IC}_{50}$ of the FVS $\left(\mathrm{SGC} \mathrm{IC}_{50}=11.99 \mu \mathrm{g} \cdot \mathrm{mL}^{-1}\right.$ ) was less than $30 \mu \mathrm{g} \cdot \mathrm{mL}^{-1}$ as seen in the standard drug (SGC $\left.\mathrm{IC}_{50}=0.88 \mu \mathrm{g} \cdot \mathrm{mL}^{-1}\right)$. According to the guidelines of the American National Cancer Institute, an extract is considered active and potential for anticancer development if it exerts an $\mathrm{IC}_{50}$ value $\leq 30 \mu \mathrm{g} \cdot \mathrm{mL}^{-1} \cdot{ }^{30}$ In contrast, the LoVo colon carcinoma cells were not significantly susceptible to the FVS, with $\mathrm{IC}_{50}>40 \mu \mathrm{g} \cdot \mathrm{mL}^{-1}$ (data not published). This was also in support of other studies in which some sterols could significantly inhibit the growth of only certain tumor cells. ${ }^{31}$ The mechanism of the FVS antitumor effect needs to be studied further.

\section{Optimized preparation of FVSMs}

Optimization of blank microemulsion formulation

Solubility study

The results of the solubility test are presented in Table 1 . The FVS could dissolve in the oily core and/or on the interface of these molecules, ${ }^{32}$ therefore the selected oily vehicles including IPM and MCT showed higher solubility values than the other oil (soybean oil). Since the IPM is mainly used as a matrix and wetting agent of cosmetics, while MCT is widely used in medicines, food, health products, and cosmetics as a semisynthetic, functional oil, the MCT was consequently selected as the oil phase for further studies. Among the surfactants and cosurfactants, FVS showed better solubility in Cremophor EL and ethanol, respectively, than in the other related vehicles. However, all the surfactants and cosurfactants were used for the ternary phase diagram study.

\section{Screening of cosurfactants}

The influence of cosurfactants on microemulsion domains is shown in Figure 3. The domain of $\mathrm{o} / \mathrm{w}$ microemulsion formation was in the area represented by "ME" in the diagram. The various diagrams of the microemulsionforming domains with ethanol were larger than that of PEG400. This implies that the ability of ethanol to serve as a good cosurfactant for the microemulsion formation was much better than PEG400. It is interesting to note that the solubility of FVS in ethanol was greater than that of PEG400 as provided by the solubility test. Consequently, the ethanol was selected as the cosurfactant for further studies. 

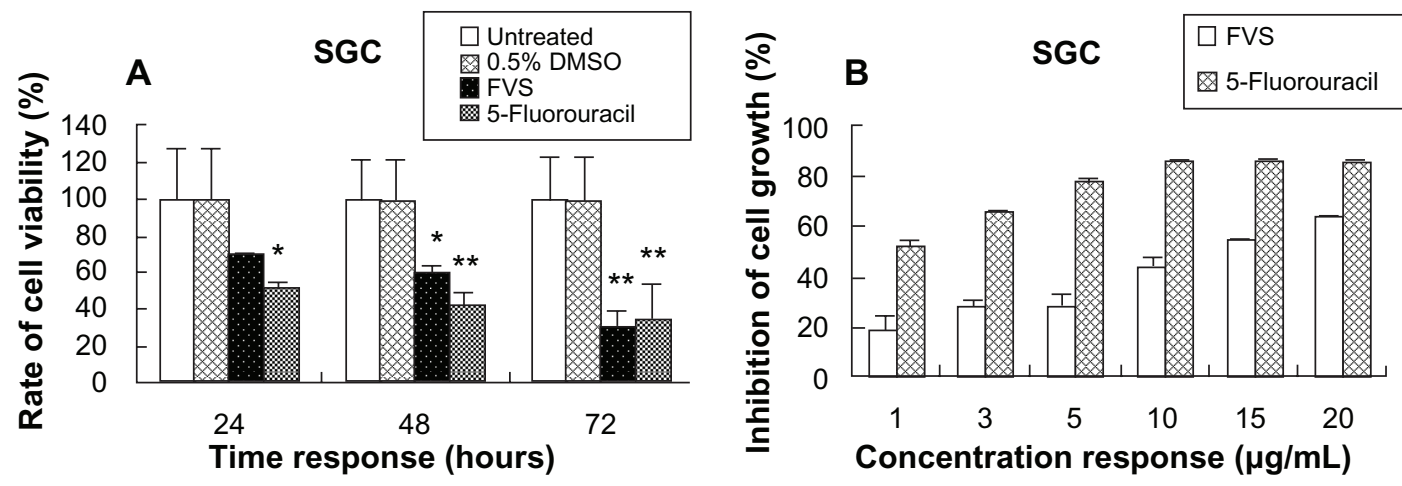

Figure 2 The cell viability of SGC cells as determined by the MTT bioassay following treatment with the vehicle control ( $0.5 \%$ DMSO), positive control (5-fluorouracil) and the test drug (FVS). The cell viability/inhibition is expressed as a percentage relative to the untreated group. Asterisks indicate significant differences $(* P<0.05$ and **P $<0.01$ ) when compared to the untreated control. (A) Cell viability of $20 \mu \mathrm{g} \cdot \mathrm{mL}^{-1}$ FVS against SGC cells at various time points. (B) Cell growth inhibition at 72 hours for the different concentrations of FVS.

Abbreviations: SGC, human gastric adenocarcinoma cell line; MTT, 3-(4, 5-dimethylthiazol-2-yl)-2, 5-diphenyltetrazolium bromide; DMSO, dimethylsulfoxide; FVS, Flammulina velutipes sterol.

\section{Screening of $K_{\mathrm{m}}$ and $K$}

When the ratio of surfactant to cosurfactant was fixed at 9:1 with respective varying ratios (from 9:1 to 1:9) of the oil to $S_{\text {mix }}$, it was observed that only at the 1:9 ratio of oil to $S_{\text {mix }}$ with the different surfactants (Tween 80, Cremophor EL, and Cremophor RH40) could clearly assist in the formation of transparent microemulsion. The accelerated high-temperature results of the nine blank microemulsions at $40^{\circ} \mathrm{C}$ and $60^{\circ} \mathrm{C}$ for 10 days showed that the formed microemulsions were only clear, transparent, and homogeneous for the 9:1 and 8:2 $K_{\mathrm{m}}$ values. However, the other microemulsions were associated with emulsion breaking and stratification, showing a decline in stability (data not shown). For a better FVS solubility in cosurfactant than in the surfactant, the value of $K_{\mathrm{m}}(8: 2)$ was selected and $K_{\mathrm{m}}(9: 1)$ was discarded.

\section{Preliminary screening of surfactant}

Based on the blank microemulsions prepared for screening $K_{\mathrm{m}}$ and $K$, the mean droplet size of microemulsion in Tween 80 group was greater than $100 \mathrm{~nm}$, indicating that Tween 80 could not be a good choice as surfactant. As a result, $K(1: 9)$, $K_{\mathrm{m}}(8: 2)$, and the surfactant (Cremophor EL for prescription
A and Cremophor RH40 for prescription B) were used as potential optimum prescriptions for further investigations.

\section{Selection of optimum FVSMs prescription}

The prescriptions A and B of FVSMs were established (Table 2). The solubility of FVS in water, $(6.70 \pm 0.93) \times 10^{-4}$ $\mathrm{mg} \cdot \mathrm{mL}^{-1}$, was extremely low compared to the prepared FVSMs $\left(0.58 \mathrm{mg} \cdot \mathrm{mL}^{-1}\right)$. The microemulsions clearly increase the solubility of FVS and could be an ideal carrier for the poorly water-soluble sterols. The improvement of the FVS loading using $\mathrm{o} / \mathrm{w}$ microemulsion depends on the solubility of the sterol in the dispersed oil phase and the percentage of that phase present. ${ }^{32}$ The results of the stability tests which were used to select the optimum prescription were as shown in the in the following sections "high temperature experiments" and "long-term experiments."

\section{High temperature experiments}

Compared with day 1 ( 0 day), the FVSMs of prescription $\mathrm{A}$ and $\mathrm{B}$ at $25^{\circ} \mathrm{C}, 40^{\circ} \mathrm{C}$, and $60^{\circ} \mathrm{C}$ for 6 days and 12 days were still clear and transparent. There was no oil-water layer separation and the droplet size was also maintained within

Table I Solubility of FVS in various vehicles at $37^{\circ} \mathrm{C}$ for 72 hours

\begin{tabular}{|c|c|c|c|c|c|c|c|c|c|}
\hline \multirow[t]{2}{*}{ Vehicles } & \multirow{2}{*}{$\frac{\text { Water phase }}{\text { Water }}$} & \multicolumn{3}{|l|}{ Oil phase } & \multicolumn{3}{|l|}{ Surfactant } & \multicolumn{2}{|c|}{ Cosurfactant } \\
\hline & & IPM & $\begin{array}{l}\text { Soybean } \\
\text { oil }\end{array}$ & МCT & $\begin{array}{l}\text { Cremophor } \\
\text { RH40 }\end{array}$ & $\begin{array}{l}\text { Cremophor } \\
\text { EL }\end{array}$ & $\begin{array}{l}\text { Tween } \\
80\end{array}$ & PEG400 & Ethanol \\
\hline $\begin{array}{l}\text { Ergosterol } \\
\left(\mathrm{mg} \cdot \mathrm{mL}^{-1}\right)\end{array}$ & $\begin{array}{l}(6.70 \pm 0.93) \times \\
10^{-4}\end{array}$ & $15.92 \pm 0.22$ & $9.65 \pm 0.02$ & $14.43 \pm 0.02$ & $8.26 \pm 0.02$ & $8.68 \pm 0.17$ & $7.32 \pm 0.25$ & $8.21 \pm 0.12$ & $14.49 \pm 0.45$ \\
\hline $\begin{array}{l}22,23- \\
\text { dihydroergosterol } \\
\left(\mathrm{mg} \cdot \mathrm{mL}^{-1}\right)\end{array}$ & - & $6.08 \pm 0.06$ & $3.25 \pm 0.26$ & $5.48 \pm 0.06$ & $3.07 \pm 0.06$ & $2.81 \pm 0.06$ & $2.87 \pm 0.03$ & $3.50 \pm 0.09$ & $4.90 \pm 0.44$ \\
\hline
\end{tabular}

Note: Mean \pm SD, $\mathrm{n}=3$.

Abbreviations: FVS, Flammulina velutipes sterol; IPM, isopropyl myristate; MCT, medium chain triglycerides; SD, standard deviation. 

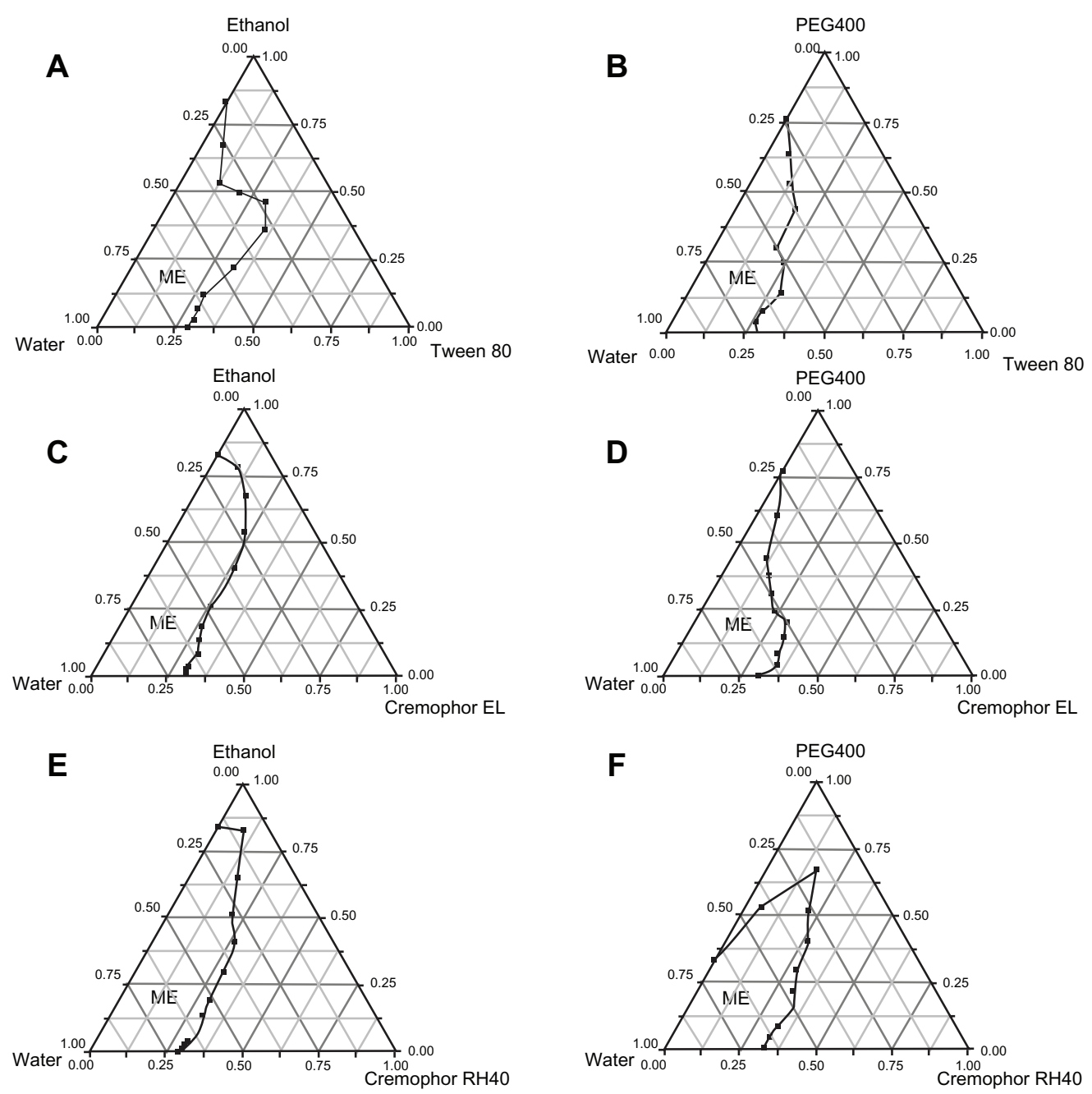

Figure 3 Ternary phase diagrams for the effect of cosurfactants on the microemulsion domain being composed of: (A) Tween 80 and ethanol; (B) Tween 80 and PEG400; (C) Cremophor EL and ethanol; (D) Cremphor EL and PEG400; (E) Cremophor RH40 and ethanol; and (F) Cremophor RH40 and PEG400 as surfactants and cosurfactants, respectively, while $10 \%$ MCT was used as oil phase.

Abbreviation: ME, o/w microemulsion region.

Table 2 Prescription composition for different FVSMs

\begin{tabular}{lllllll}
\hline Prescription & Cremophor RH40 $(\mathbf{g})$ & Cremophor EL $(\mathbf{g})$ & Ethanol $(\mathbf{g})$ & $\begin{array}{l}\text { MCT } \\
(\mathbf{g})\end{array}$ & $\begin{array}{l}\text { Sterols } \\
(\mathbf{m g})\end{array}$ & $\begin{array}{l}\text { Water } \\
(\mathbf{g})\end{array}$ \\
\hline A & - & 7.21 & 1.81 & 1.01 & 19.9 & 24.49 \\
B & 7.22 & - & 1.82 & 1.01 & 20.0 & 24.35 \\
\hline
\end{tabular}

Abbreviations: FVSMs, Flammulina velutipes sterol liposomes; MCT, medium chain triglycerides.

Table 3 Effect of different temperatures on the stability of FVSMs

\begin{tabular}{|c|c|c|c|c|c|c|c|c|c|c|c|}
\hline \multirow[t]{3}{*}{ Prescription } & \multirow[t]{3}{*}{ Time (days) } & \multirow[t]{3}{*}{ Appearance } & \multicolumn{6}{|c|}{ Sterol content $\left(\mathbf{m g} \cdot \mathbf{g}^{-1}\right)$} & \multicolumn{3}{|c|}{ Droplet size $(\mathrm{nm})$} \\
\hline & & & \multicolumn{3}{|c|}{ Ergosterol } & \multicolumn{3}{|c|}{ 22,23-dihydroergosterol } & \multirow[t]{2}{*}{$\mathbf{R T}$} & \multirow[t]{2}{*}{$40^{\circ} \mathrm{C}$} & \multirow[t]{2}{*}{$60^{\circ} \mathrm{C}$} \\
\hline & & & RT & $40^{\circ} \mathrm{C}$ & $60^{\circ} \mathrm{C}$ & RT & $40^{\circ} \mathrm{C}$ & $60^{\circ} \mathrm{C}$ & & & \\
\hline \multirow[t]{3}{*}{ A } & 0 & Uniform & 0.287 & 0.287 & 0.287 & 0.106 & 0.106 & 0.106 & 30.0 & 30.0 & 30.0 \\
\hline & 6 & Uniform & 0.282 & 0.285 & 0.265 & 0.106 & 0.104 & 0.101 & - & - & - \\
\hline & 12 & Uniform & 0.272 & 0.251 & 0.045 & 0.104 & 0.096 & 0.013 & 27.8 & 37.4 & 24.8 \\
\hline \multirow[t]{3}{*}{ B } & 0 & Uniform & 0.289 & 0.289 & 0.289 & 0.107 & 0.107 & 0.107 & 22.9 & 22.9 & 22.9 \\
\hline & 6 & Uniform & 0.272 & 0.227 & 0.092 & 0.102 & 0.085 & 0.033 & - & - & - \\
\hline & 12 & Uniform & 0.255 & 0.115 & 0.021 & 0.092 & 0.042 & 0.010 & 26.5 & 20.6 & 20.6 \\
\hline
\end{tabular}

Notes: -, no droplet size measurement was taken. Ergosterol and 22,23-dihydroergosterol were used as FVS content assessment indicators.

Abbreviations: FVS, Flammulina velutipes sterol; FVSMs, Flammulina velutipes sterol liposomes; MCT, medium chain triglycerides. 


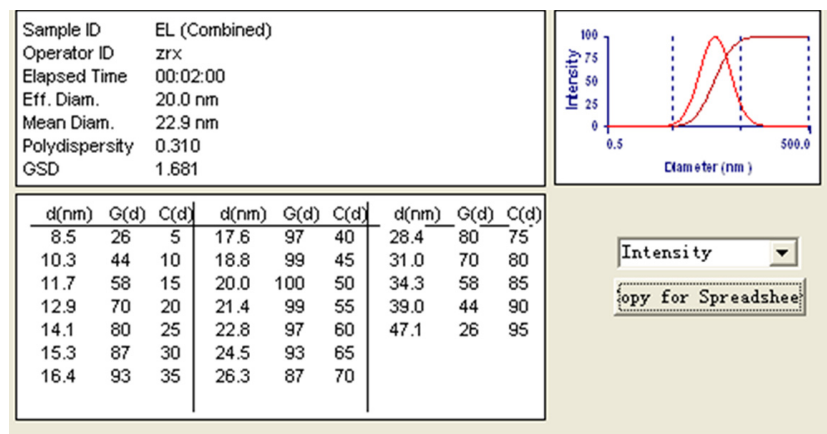

Figure 4 Droplet size of optimized FVSMs prescription at $0.68 \mathrm{mg} \cdot \mathrm{mL}^{-1}$ Abbreviations: FVSMs, Flammulina velutipes sterol liposomes; FVS, Flammulina velutipes sterol.

$20 \sim 40 \mathrm{~nm}$. At $25^{\circ} \mathrm{C}, 40^{\circ} \mathrm{C}$, and $60^{\circ} \mathrm{C}$ for 12 days, the contents of ergosterol and 22,23-dihydroergosterol in prescription A were respectively $95 \%$ and $98 \%, 87 \%$ and $91 \%, 16 \%$ and $12 \%$, compared with $100 \%$ at 0 day. Similarly, the contents in prescription B were respectively $88 \%$ and $86 \%, 40 \%$ and $39 \%, 7 \%$ and $9 \%$, compared with 0 day (Table 3 ). The results showed that the degradation rate of the FVS content was faster at very high temperatures, indicating that the FVSMs need to be stored at lower temperatures, which was in agreement with other related studies. ${ }^{33}$ Comparatively, the degradation rate of FVS in prescription $\mathrm{B}$ was greater than $\mathrm{A}$, which may be explained by the better stability of Cremophor EL in prescription A than Cremophor RH40 in prescription B at high temperatures.

\section{Long-term experiments}

The FVSMs for prescription A were still clear and transparent with no oil-water layer separation for the 30-day period of study at $25^{\circ} \mathrm{C}$. However, the FVSMs for prescription B had

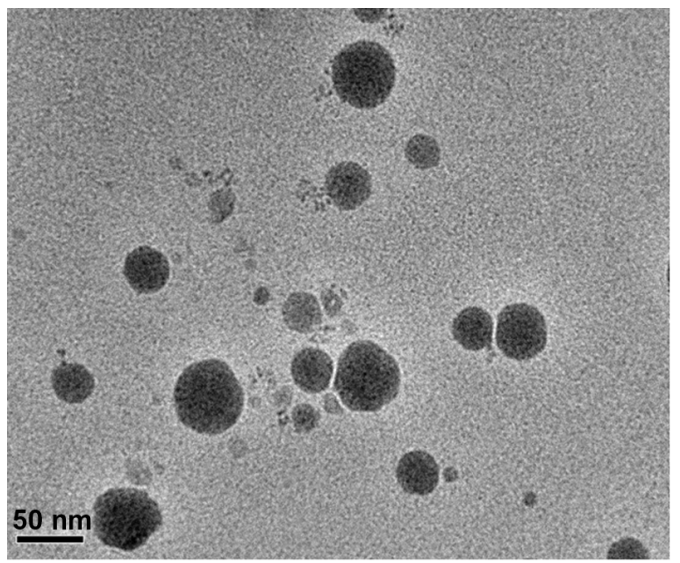

Figure 5 Transmission electron microscope image of optimized FVSMs prescription.

Abbreviation: FVSMs, Flammulina velutipes sterol liposomes.
Table 4 Effect of $4^{\circ} \mathrm{C}$ on the stability of FVSMs

\begin{tabular}{llll}
\hline $\begin{array}{l}\text { Time } \\
\text { (days) }\end{array}$ & Dispersion & \multicolumn{2}{l}{ FVS $\left(\mathbf{m g} \cdot \mathbf{~ m L}^{-1}\right)$} \\
\cline { 3 - 4 } & & Ergosterol & $\mathbf{2 2 , 2 3 - d i h y d r o e r g o s t e r o l ~}$ \\
\hline 0 & Uniform & 0.344 & 0.121 \\
7 & Uniform & 0.336 & 0.117 \\
14 & Uniform & 0.338 & 0.118 \\
21 & Uniform & 0.330 & 0.112 \\
\hline
\end{tabular}

Note: Ergosterol and 22,23-dihydroergosterol were used as FVS content assessment indicators.

Abbreviations: FVSMs, Flammulina velutipes sterol liposomes; FVS, Flammulina velutipes sterol.

demulsification and oil-water layer separation, indicating that prescription A was more stable than prescription B when it comes to long-term storage.

Based on the stability test results, the FVSMs prescription A was selected for further studies with a ratio of Cremophor EL to ethanol to MCT to water being 7.2: 1.8: 1.0: 24.4, respectively. The microemulsions used in this study were all prepared according to prescription $\mathrm{A}$ and $30 \mathrm{~mL}$ of FVSMs with drug loading of up to $0.680 \mathrm{mg} \cdot \mathrm{mL}^{-1}$ was used. The content of FVS in microemulsions decreased faster at $60^{\circ} \mathrm{C}$, but other indicators (appearance and droplet size) had slight or no changes on FVSMs (Table 3). The stability of FVSMs in vivo needs to be further studied because of the differences in conditions between in vivo and in vitro environments.

\section{Characterization of FVSMs}

FVSMs were a clear colorless and transparent liquid with very good fluidity (low viscosity). The water-soluble dye

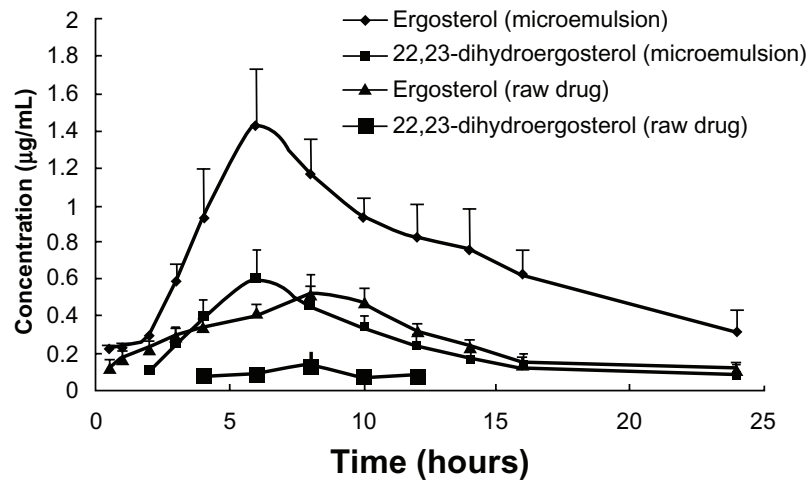

Figure 6 Plasma concentration-time profiles of FVS (ergosterol and 22,23dihydroergosterol) after oral administration of free FVS suspension and FVS-loaded microemulsion (FVSMs) at $100 \mathrm{mg} \cdot \mathrm{kg}^{-1}$ dose to rats.

Notes: Each value represents the mean \pm SD of five rats. Ergosterol and 22,23dihydroergosterol were used as FVS content assessment indicators. Mean ( \pm SD) plasma concentration-time profile of ergosterol and 22,23-dihydroergosterol in the loaded-microemulsions and free ergosterol and 22,23-dihydroergosterol in the plasma which were orally administered to healthy rats $(n=5)$ at a dose of $100 \mathrm{mg} \cdot \mathrm{kg}^{-1}$ of $5 \mathrm{mg} \cdot \mathrm{mL}^{-1}$.

Abbreviations: FVSMs, Flammulina velutipes sterol liposomes; FVS, Flammulina velutipes sterol; SD, standard deviation. 
Table 5 Pharmacokinetic parameters of oral administration of FVSMs in rats

\begin{tabular}{lccccc}
\hline Parameters & FVSMs & & Free FVS & \\
\cline { 2 - 3 } \cline { 5 - 6 } & Ergosterol & 22,23-dihydroergosterol & & Ergosterol & 22,23-dihydroergosterol \\
\hline$C_{\max }\left(\mu \mathrm{g} \cdot \mathrm{mL}^{-1}\right)$ & $1.457 \pm 0.573$ & $0.712 \pm 0.153$ & $6 \pm 0$ & $0.525 \pm 0.091$ & $0.138 \pm 0.068$ \\
$T_{\max } / \mathrm{h}$ & $7 \pm 2$ & $4.245 \pm 0.520$ & $8 \pm 0$ & $7.333 \pm 1.155$ \\
$t_{1 / 2} / \mathrm{h}$ & $5.802 \pm 0.843$ & $6.093 \pm 1.262$ & & $4.753 \pm 0.708$ & $9.123 \pm 4.810$ \\
$\mathrm{AUC}$ & $16.497 \pm 4.44$ & $6.432 \pm 0.812$ & $1.354 \pm 0.349$ \\
\hline
\end{tabular}

Notes: Each value is the mean \pm SD of five rats. Ergosterol and 22,23-dihydroergosterol were used as FVS content assessment indicators.

Abbreviations: FVSMs, Flammulina velutipes sterol liposomes; FVS, Flammulina velutipes sterol; SD, standard deviation; AUC, area under the (plasma concentration time) curve.

methylene blue diffused faster than the oil-soluble dye Sudan red in both blank microemulsions and FVSMs, indicating that the two kinds of microemulsions were $\mathrm{o} / \mathrm{w}$ microemulsions. The mean droplet size of FVSMs was $22.9 \mathrm{~nm}$ with a polydispersity index value of 0.31 (Figure 4), and the range of droplet size distribution was relatively narrow $(8.5-47.1 \mathrm{~nm})$. The mean droplet size was smaller than those found in other related studies. ${ }^{10,32,34}$ The zeta potential of FVSMs was zero according to the result of the zeta potential analysis (data not shown), which indicated that there was no electrostatic action among the microemulsion drops. The morphology of microemulsions observed by TEM was spherical (Figure 5), and the result of droplet size was consistent with that determined by the particle detector. The average viscosity of FVSMs which was measured by the Brookfield viscometer was $122.8 \mathrm{mPa}(50 \mathrm{rpm}$ of spinning, 8.11 $\mathrm{Pa}$ of shear stress, $66 \mathrm{~s}^{-1}$ of shear rate, and $28.12^{\circ} \mathrm{C}$ temperature). The content of ergosterol and 22,23-dihydroergosterol in FVSMs was $0.344 \mathrm{mg} \cdot \mathrm{mL}^{-1}$ and $0.121 \mathrm{mg} \cdot \mathrm{mL}^{-1}$, respectively with the encapsulation efficiency being $81.1 \% \pm 1.2 \%$. This indicates that most of the FVS was entrapped in the microemulsion. The results were in line with other current studies. ${ }^{17,35}$ The standard features of FVSMs after the accelerated centrifugal experiment, dilution test, and low-temperature test were still unchanged with clear and transparent appearances. There were also no oil-water layer separation, nonprecipitation of FVS, and the content of ergosterol and 22,23-dihydroergosterol changed slightly in the low-temperature test (Table 4). This indicates that FVSMs were physicochemically stable as reported by previous studies. ${ }^{32}$ Microemulsions could be diluted by water in the gastrointestinal tract upon oral administration, which could lead to drug precipitation. Therefore, the nonprecipitation of the FVSMs after several dilutions is also a good step in the right direction. The solubility of FVS, a poorly water-soluble drug, was promoted to $0.680 \mathrm{mg} \cdot \mathrm{mL}^{-1}$ by an optimum microemulsion formulation composed of
3.0\% MCT (oil), 21.0\% Cremophor EL (surfactant), 5.0\% ethanol (cosurfactant), and $71.0 \%$ water.

\section{In vivo studies}

\section{Pharmacokinetics of FVSMs in rats}

The plasma concentration profiles of FVS are shown in Figure 6. The pharmacokinetic parameters are also summarized in Table 5. The area under the curve of ergosterol and 22,23-dihydroergosterol in the FVSMs group increased to about 2.56-fold and 4.50-fold, respectively, as compared to the free FVS group. This also confirms the results of improved oral bioavailability for the FVSMs, which was supported by other studies on microemulsion. ${ }^{36}$ Similar trend was also seen in the maximum concentration of ergosterol and 22,23dihydroergosterol, which increased to about 2.78-fold and 5.16-fold, respectively, with FVSMs oral administration as against the free FVS. The improved oral bioavailability could be due to the predominant improved solubility of sterols in microemulsions which kept the drug in the soluble form during the gastrointestinal dilution and permeation process and the synergistic effect of oil and surfactants as absorption enhancers. ${ }^{37}$ The time to maximum concentration of ergosterol and 22,23-dihydroergosterol was relatively shortened for 1 and 1.33 hours in the FVSMs group compared with the free FVS group. This supports the finding that the FVSMs could dissolve rapidly in the gastrointestinal tract. Furthermore, the rapid increase in the delivery of the sterol could achieve high drug concentrations in the tract leading to good oral absorption.

\section{Conclusion}

The free FVS was able to inhibit the growth of human SGC tumor cells in the in vitro studies. This indicates that FVS could play an important role in the studies of many different human cancer cells in the near future. The optimum $\mathrm{o} / \mathrm{w}$ microemulsion formulation consisted of $3.0 \% \mathrm{MCT}$ (oil), $21.0 \%$ Cremophor EL (surfactant), 5.0\% ethanol (cosurfactant), and $71.0 \%$ water, which enhanced the solubility 
of FVS up to $0.680 \mathrm{mg} \cdot \mathrm{mL}^{-1}$ compared with the free FVS $\left([6.70 \pm 0.93] \times 10^{-4} \mathrm{mg} \cdot \mathrm{mL}^{-1}\right)$. In addition, the pharmacokinetic study in rats revealed an improved oral bioavailability of FVSMs.

\section{Acknowledgments}

This work was supported by National Natural Science Foundation of China (30973677), Doctoral Fund of Ministry of Education of China (20113227110012), and industryuniversity-research institution cooperation (BY2009141, CY2010023, GY2011028) in Jiangsu Province and Zhenjiang City. The authors also thank the Jiangsu University Ethics Committee for their kind guidance in the animal experiments.

\section{Disclosure}

The authors have no conflict of interest to disclose.

\section{References}

1. Fukushima M, Ohashi T, Fujiwara Y, Sonoyama K, Nakano M. Cholesterol-lowering effects of maitake (Grifola frondosa) fiber, shiitake (Lentinus edodes) fiber, and enokitake (Flammulina velutipes) fiber in rats. Exper Biol Med (Maywood). 2001;226(8): 758-765.

2. Ge ZW, Yang ZL, Zhang P, Matheny PB, Hibbett DS. Flammulina species from China inferred by morphological and molecular data. Fungal Divers. 2008;32:59-68.

3. Tereshina VM, Memorskaya AS. Adaptation of Flammulina velutipes to hypothermia in natural environments: The role of lipids and carbohydrates. Microbiology. 2005;74(3):279-283.

4. Yang JH, Lin HC, Mau JL. Non-volatile taste components of several commercial mushrooms. Food Chem. 2001;72(4):465-471.

5. Song CH, Jeon YJ, Yang BK, Ra KS, Kim HI. Anti-complementary activity of endopolymers produced from submerged mycelial culture of higher fungi with particular reference to Lentinus edodes. Biotechnol Lett. 1998;20(8):741-744.

6. Ishikawa NK, Fukushi Y, Yamaji K, Tahara S, Takahashi K. Antimicrobial cuparene-type sesquiterpenes, enokipodins $\mathrm{C}$ and $\mathrm{D}$, from a mycelial culture of Flammulina velutipes. J Nat Prod. 2001;64(7): 932-934.

7. Jang SG, Jeon KS, Lee EH, Kong WS, Cho JY. Isolation of 1',3'dilinolenoyl-2'-linoleoylglycerol with tyrosinase inhibitory activity from Flammulina velutipes. J Microbiol Biotechnol. 2009;19(7): 681-684.

8. Ishikawa NK, Yamaji K, Tahara S, Fukushi Y, Takahashi K. Highly oxidized cuparene-type sesquiterpenes from a mycelial culture of Flammulina velutipes. Phytochemistry. 2000;54(8):777-782.

9. Hsieh KY, Hsu CI, Lin JY, Tsai CC, Lin RH. Oral administration of an edible-mushroom-derived protein inhibits the development of food-allergic reactions in mice. Clin Exper Allergy. 2003;33(11): $1595-1602$.

10. Ko WC, Liu WC, Tsang YT, Hsieh CW. Kinetics of winter mushrooms (Flammulina velutipes) microstructure and quality changes during thermal processing. J Food Engin. 2007;81(3):587-598.

11. Lee KJ, Yun IJ, Kim KH, et al. Amino acid and fatty acid compositions of Agrocybe chaxingu, an edible mushroom. J Food Compost Anal. 2011;24(2):175-178.

12. Kogan A, Garti N. Microemulsions as transdermal drug delivery vehicles. Adv Colloid Interface Sci. 2006;123:369-385.

13. Constantinides PP. Lipid microemulsions for improving drug dissolution and oral absorption: physical and biopharmaceutical aspects. Pharm Res. 1995;12(11):1561-1572.
14. Shah NH, Carvajal MT, Patel CI, Infeld MH, Malick AW. Self-emulsifying drug delivery systems (SEDDS) with polyglycolyzed glycerides for improving in vitro dissolution and oral absorption of lipophilic drugs. Int J Pharm. 1994;106(1):15-23.

15. Lawrence MJ, Rees GD. Microemulsion-based media as novel drug delivery systems. Adv Drug Deliv Rev. 2000;45(1):89-121.

16. Gao ZG, Choi HG, Shin HJ, et al. Physicochemical characterization and evaluation of a microemulsion system for oral delivery of cyclosporin A. Int J Pharm. 1998;161(1):75-86.

17. Yin YM, Cui FD, Mu CF, et al. Docetaxel microemulsion for enhanced oral bioavailability: Preparation and in vitro and in vivo evaluation. J Control Release. 2009;140(2):86-94.

18. Zhang H, Cui Y, Zhu S, Feng F, Zheng X. Characterization and antimicrobial activity of a pharmaceutical microemulsion. Int J Pharm. 2010;395(1):154-160.

19. Förster T, Von Rybinski W, Wadle A. Influence of microemulsion phases on the preparation of fine-disperse emulsions. Adv Colloid Interface Sci. 1995;58(2):119-149.

20. Lagues M, Sauterey C. Percolation transition in water in oil microemulsions. Electrical conductivity measurements. J Phys Chem. 1980;84(26):3503-3508.

21. Aboofazeli R, Lawrence MJ. Investigations into the formation and characterization of phospholipid microemulsions. I. Pseudo-ternary phase diagrams of systems containing water-lecithin-alcohol-isopropyl myristate. Int J Pharm. 1993;93(1-3):161-175.

22. Trotta M, Ugazio E, Gasco MR. Pseudo-ternary phase diagrams of lecithin-based microemulsions: influence of monoalkylphosphates. J Pharm Pharmacol. 1995;47(6):451-454.

23. Rege BD, Kao JPY, Polli JE. Effects of nonionic surfactants on membrane transporters in Caco-2 cell monolayers. Eur J Pharm Sci. 2002;16(4-5):237-246.

24. Lin Y, Shen Q, Katsumi H, et al. Effects of Labrasol and other pharmaceutical excipients on the intestinal transport and absorption of rhodamine123, a P-glycoprotein substrate, in rats. Biol Pharm Bull. 2007;30(7):1301-1307.

25. Takahashi Y, Kondo H, Yasuda T, Watanabe T, Kobayashi SI, Yokohama S. Common solubilizers to estimate the Caco-2 transport of poorly water-soluble drugs. Int J Pharm. 2002;246(1): 85-94.

26. Zhang Q, Jiang X, Jiang W, Lu W, Su L, Shi Z. Preparation of nimodipine-loaded microemulsion for intranasal delivery and evaluation on the targeting efficiency to the brain. Int J Pharm. 2004;275(1): 85-96.

27. Chu C, Tong S, Xu Y, et al. Proliposomes for oral delivery of dehydrosilymarin: preparation and evaluation in vitro and in vivo. Acta Pharmacol Sin. 2011;32(7):973-980.

28. Pitaksuteepong T, Davies NM, Tucker IG, Rades T. Factors influencing the entrapment of hydrophilic compounds in nanocapsules prepared by interfacial polymerisation of water-in-oil microemulsions. Eur J Pharm Biopharm. 2002;53(3):335-342.

29. Yaoita Y, Amemiya K, Ohnuma H, et al. Sterol constituents from five edible mushrooms. Chem Pharm Bull. 1998;46(6):944-950.

30. Suffness M, Pezzuto JM. Assays related to cancer drug discovery. Methods in Plant Biochemistry: Assays for Bioactivity. 1990;6: 71-133.

31. Yasukawa K, Aoki T, Takido M, Ikekawa T, Saito H, Matsuzawa T. Inhibitory effects of ergosterol isolated from the edible mushroom Hypsizigus marmoreus on TPA-induced inflammatory ear oedema and tumour promotion in mice. Phytother Res. 1994;8(1):10-13.

32. Hu L, Wu H, Niu F, Yan C, Yang X, Jia Y. Design of fenofibrate microemulsion for improved bioavailability. Int J Pharm. 2011; 420(2):251-255.

33. Constantinides PP, Yiv SH. Particle size determination of phase-inverted water-in-oil microemulsions under different dilution and storage conditions. Int J Pharm. 1995;115(2):225-234.

34. Tsai YH, Lee KF, Huang YB, Huang CT, Wu PC. In vitro permeation and in vivo whitening effect of topical hesperetin microemulsion delivery system. Int J Pharm. 2010;388(1-2):257-262. 
35. Shima M, Kobayashi Y, Kimura Y, Adachi S, Matsuno R. Effect of the hydrophilic surfactants on the preparation and encapsulation efficiency in course and fine W/O/W type emulsions. Colloids Surf A Physicochem Eng Asp. 2004;238(1):83-90.

36. Gannu R, Palem CR, Yamsani VV, Yamsani SK, Yamsani MR. Enhanced bioavailability of lacidipine via microemulsion based transdermal gels: Formulation optimization, ex vivo and in vivo characterization. Int $J$ Pharm. 2010;388(1-2):231-241.
37. Li X, Yue Y, Zhou Y, et al. An oil-free microemulsion for intravenous delivery of diallyl trisulfide: Formulation and evaluation. Int J Pharm. 2011;407(1-2):158-166.

\section{Publish your work in this journal}

The International Journal of Nanomedicine is an international, peerreviewed journal focusing on the application of nanotechnology in diagnostics, therapeutics, and drug delivery systems throughout the biomedical field. This journal is indexed on PubMed Central, MedLine, CAS, SciSearch $\AA$, Current Contents ${ }^{\circledR} /$ Clinical Medicine,
Journal Citation Reports/Science Edition, EMBase, Scopus and the Elsevier Bibliographic databases. The manuscript management system is completely online and includes a very quick and fair peer-review system, which is all easy to use. Visit http://www.dovepress.com/ testimonials.php to read real quotes from published authors.

Submit your manuscript here: http://www.dovepress.com/international-journal-of-nanomedicine-journal 